\title{
Behavior of RC Beam-Column Joints Strengthened with Modified Reinforcement Techniques
}

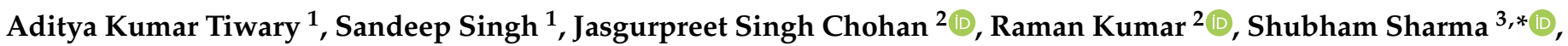 \\ Somnath Chattopadhyaya ${ }^{4}$, Farid Abed ${ }^{5}(\mathbb{D}$ and Mislav Stepinac $6, *(1)$
}

1 Civil Engineering Department, Chandigarh University, Mohali 140413, Punjab, India; aditya.civil@cumail.in (A.K.T.); drsandeep1786@gmail.com (S.S.)

2 Mechanical Engineering Department, Chandigarh University, Mohali 140413, Punjab, India; jaskhera@gmail.com (J.S.C.); ramankakkar@gmail.com (R.K.)

3 Department of Mechanical Engineering, IK Gujral Punjab Technical University, Main Campus-Kapurthala, Kapurthala 144603, Punjab, India

4 Department of Mechanical Engineering, Indian Institute of Technology (ISM), Dhanbad 826004, Jharkhand, India; somnathchattopadhyaya@iitism.ac.in

5 Department of Civil Engineering, American University of Sharjah, Sharjah P.O. Box 26666, United Arab Emirates; fabed@aus.edu

6 Faculty of Civil Engineering, University of Zagreb, 10000 Zagreb, Croatia

* Correspondence: shubham543sharma@gmail.com or shubhamsharmacsirclri@gmail.com (S.S.); mislav.stepinac@grad.unizg.hr (M.S.)

check for updates

Citation: Tiwary, A.K.; Singh, S.; Chohan, J.S.; Kumar, R.; Sharma, S.; Chattopadhyaya, S.; Abed, F.; Stepinac, M. Behavior of RC Beam-Column Joints Strengthened with Modified Reinforcement Techniques. Sustainability 2022, 14, 1918. https://doi.org/10.3390/ su14031918

Academic Editor: Francesca Tittarell

Received: 29 December 2021

Accepted: 4 February 2022

Published: 8 February 2022

Publisher's Note: MDPI stays neutral with regard to jurisdictional claims in published maps and institutional affiliations.

Copyright: (C) 2022 by the authors. Licensee MDPI, Basel, Switzerland. This article is an open access article distributed under the terms and conditions of the Creative Commons Attribution (CC BY) license (https:// creativecommons.org/licenses/by/ $4.0 /)$.

\begin{abstract}
Using a significant number of transverse hoops in the joint's core is one recognized way for achieving the requirements of strength, stiffness, and ductility under dynamic loading in a column joint. The shear capacity of a joint is influenced by the concrete's compressive strength, the anchoring of longitudinal beam reinforcement, the number of stirrups in the joint, and the junction's aspect ratio. Seismic motion on the beam may produce shear capacity and bond breaking in the joint, causing the joint to fracture. Furthermore, due to inadequate joint design and details, the entire structure is jeopardized. In this study, the specimens were divided into two groups for corner and interior beam-column joints based on the joint reinforcement detailing. The controlled specimen has joint detailing as per IS 456:2000, and the strengthened specimen has additional diagonal cross bars (modified reinforcement technique) at the joints detailed as per IS 456:200. The displacement time history curve, load-displacement response curves, load-displacement hysteretic curve, and load cycle vs. shear stress were used to compare the results of the controlled and strengthened specimens. The findings show that adding diagonal cross bars (modified reinforcing techniques) to beam-column joints exposed to cyclic loads enhances their performance. The inclusion of a diagonal cross bar increased the stiffness of the joint by giving an additional mechanism for shear transfer and ductility, as well as greater strength with minimum cracks.
\end{abstract}

Keywords: beam-column joints; shear capacity; cyclic loading; joint's numerical modeling; interior joint; corner joint; modified reinforcement technique (MRT)

\section{Introduction}

The beam-column joint is the crucial zone in a reinforced concrete $(\mathrm{RC})$ frame subjected to large forces during several ground shaking events, and its behavior has a significant influence on the response of the structure. Beam-column joints are the link between horizontal and vertical structural elements, and therefore, the joints are directly involved in the transfer of seismic forces [1]. The strength of the joint's component materials is restricted, and the joint's force-carrying capacity is also restricted. As a result, joints can be severely damaged or even destroyed during an earthquake [2,3]. The primary cause of joint failure is insufficient joint shear strength, which occurs due to insufficient and inadequate reinforcing details at the junction region [4]. Since fixing a fractured joint is challenging, the damage 
level needs to be minimized at the construction stage using a variety of techniques. An earthquake-resistant frame's column should be stronger than its beam. Joint panel stirrups contribute to the confining pressure and shear strength required to prevent early brittle collapses; the movement between the columns and beams can be transmitted correctly with enough transverse reinforcement [5]. However, structural elements constructed against gravity loads or in line with seismic standards in the Mediterranean region usually lack transverse reinforcements in the junction [6-9].

Consequently, beam-column junctions have been recognized among the principal causes of damage in pre-existing reinforced concrete $(\mathrm{RC})$ structures in various studies conducted in the context of prior significant earthquakes. In most countries vulnerable to seismic events, pre-seismic codes do not meet present standards for reinforced concrete structures [10]. Earthquakes that have occurred recently (e.g., M7.4 Oaxaca (Mexico), M7.0 Aegean Sea (Turkey-Greece), M6.4 Croatia) have mostly caused failures of masonry buildings, but RC buildings were also, in some cases, heavily damaged [11-13]. One reason is that the beam-column joints in moment-resisting RC frame constructions have enough shear strength and ductility [14].

A design guideline for achieving the appropriate strength for beam-column joints is included in the existing standards. These specifications include enough anchoring for both beam and column bars traveling through or terminating in the joint area, and appropriate flexural strength for the beam and column to ensure beam-failure mechanisms [15,16]. Tsonos et al. [17] gave an overview of modern design codes (Eurocode family of codes) for the seismic performance of RC beam-column joints and compared them with the older standards. A simplified model for strengthening RC beam-column internal joints is given by Bossio et al. [1], which could be used by designers of new joints to quantify the performance of new structures, as well as by designers of external strengthening of existing joints to compute the benefits of the retrofit and shift the initial failure mode to a more desirable one.

In order to improve the structural behavior of precast beam-column connections, Hanif and Kanakubo [18] studied the use of fiber-reinforced cementitious composite (FRCC) to grout the joint region. Under reversed cyclic stress, two full-scale internal beam-column junctions were evaluated. In the joint region of the first specimen, aramid fibers cementitious composite was used. At the same time, polypropylene fibers cementitious composite was utilized to grout the junction in the second specimen. The findings were compared to previous research (no fibers, PVA fibers, and steel fibers). In contrast, steel fibers had considerably increased shear capacity and the largest hysteretic region. According to the test findings, PVA fibers outperformed others in terms of fracture width. In contrast, steel fibers had considerably increased shear capacity and the largest hysteretic region.

Li et al. [19] studied the cyclic behavior of joints built using prefabricated beams and columns composed of engineered cementitious composite (ECC). Two large-scale joint specimens made of conventional concrete and three large-scale joint specimens constructed of ECC were fabricated and tested under cyclic stresses till failure. One specimen was manufactured monolithically and served as a control. The effects of bar splicer sleeves and the connection location on the load-carrying capacity, failure mode, and ductility of produced joints were evaluated using three alternative assembly strategies. ECC enhanced the load-carrying capacity and ductility of constructed joints, according to the findings. The inclusion of longitudinal bars and splicer sleeves increased the load-carrying capacity but reduced ductility because the failure mechanism shifted from flexural to shear. The cyclic behavior was indifferent to connection location when ECC was employed.

The volume percentage of steel fibers in concrete and the detailing of reinforced steel in external beam-column joints were studied by Oinam et al. [20]. Regardless of transverse reinforcement in the joints, specimens of longitudinal beam bars positioned diagonally in the beam-column joints revealed interfacial shear fractures, according to the test findings. Those with a straight longitudinal bar in beams, on the other hand, showed a flexural plastic hinge away from the joint location. Steel fiber-reinforced concrete (SFRC) in the joint's 
region demonstrated outstanding ductility, energy absorption, and consistent hysteresis response, despite increasing the spacing of the hoops in the beam-column joints region.

Ravichandran [21] tested fourteen specimens under cyclic loads, one of which was built according to seismic code IS 13920 [22]. In contrast, the others were built without seismic details according to American Concrete Institute (ACI 318) [23], with HyFRC substituting regular concrete in the joint's location. For each volume fraction, two specimens were cast using the same concrete grade with hybrid fibers $(80 \%$ steel $+20 \%$ polyolefin and $60 \%$ steel $+40 \%$ polyolefin) $(0.5 \%, 1 \%, 1.5 \%$, and $2 \%)$. The findings revealed that high-strength concrete containing $80 \%$ steel and $20 \%$ polyolefin improved ductility, energy absorption, and overall strength across all volume fractions. However, when compared to the seismic detail specimen, the hybrid fibers specimen with a volume fraction of $2 \%(80 \%$ steel $/ 20 \%$ polyolefin) outperformed the seismic detail specimen in terms of energy absorption capacity and ductility.

Six beam-column knee joint specimens were constructed utilizing five created hybrid synthetic fibers, and one control specimen was evaluated under lateral cyclic stress by Zainal et al. [24]. Ferro-Ultra (F6U3), Ferro-Super (F6S3), Ferro-Econo (F6E3), and FerroNylo (F6N3) were used to cast the hybrid fiber-reinforced concrete (HyFRC) joint area (FFC). According to the findings, the HyFRC joints showed substantial improvements in energy dissipation capacity, stiffness degradation rate, and displacement ductility. Compared to the reference specimens, the F6U3 generated the most augmentation, while the FFC produced the least. All hybrid specimens were numerically simulated using the finiteelement method. The average margin error for peak load capacity, peak load displacement, and maximum displacements was $25.89 \%, 3.45 \%$, and $0.18 \%$, respectively.

Dehghani et al. [25] built a 3D finite-element model to analyze the impact of employing ECC in various patterns of beam-column connections. The model's validity was determined based on Yuan et al.'s findings [26]. The ECC material enhanced the load-carrying capacity and ductility of the beam-column connections but did not affect their initial stiffness. Furthermore, employing ECC outside of the plastic hinge areas was useless, as most tensile and shear cracks are found within the joints. The findings also showed that ECC was ineffective for preventing the diagonal shear crack in the joint area. Alwash et al. [27] and Bossio et al. [28] studied the corrosion of RC joints when exposed to bending moment and axial forces. Their study was oriented on the loss of integrity, a decrease of load-bearing capacity, stiffness, and serviceability due to corrosion, and the on joints' rehabilitation with the patch repair technique (PRT).

The steel plate energy absorption device (SPEAD) system, presented by Giuseppe Santarsiero et al. [29], is a revolutionary strengthening approach that aims to boost the flexural strength of beam and column components in RC frame constructions. The updated SPEAD model produced a 50-percent increase in strength, as well as a significant reduction in bond-slip effects in the joint panel region. This, in turn, resulted in an increase in ductility, which was good.

The concrete compressive strength, joint aspect ratio, and a number of lateral connections inside the joint are the most critical parameters determining the shear capacity of $\mathrm{RC}$ beam-column joints. A modified reinforcing technique to increase the shear capacity of cyclically loaded RC beam-column junctions is a viable option. The primary concerns discovered in the literature examined are the anchoring length requirements for beam bars, the provision of transverse reinforcements, and the involvement of stirrups in shear transmission at the joint. Research evaluating the use of extra cross-inclined bars at the joint core found that the inclined bars contribute a novel method of shear transfer, reducing the risk of a diagonal cleavage fracture at the joint. According to major international standards, diagonal cross bars have no effect on the shear strength of a joint. The goal of this study was to enhance core concrete confinement while avoiding reinforcing congestion in joints. The inclusion of diagonal bars adds another mechanism for shear transmission. 


\subsection{Interior Beam-Column Joint}

In most instances, the breakdown of inner beam-column junctions triggered the failure mechanism in buildings. The statement mentioned above is proven by a thorough analysis of numerous collapsed or seriously damaged pre-seismic code-designed RCframed structures after moderate or major earthquakes [2,3]. As a result, the weakest connection in existent RC movement-resistant frames was identified as the beam-column joints. These joints' inadequate shear strength has been established as the primary cause of joint failure. This lack in strength is commonly caused by insufficient and poorly specified joint reinforcements [30-32].

Furthermore, joint brittleness develops due to deficient reinforcement, especially the joint's transverse reinforcement causing a reduction in the overall ductility of the construction. The modified reinforcing technique aids in transferring shear or provides an extra shear-transfer mechanism at the joint. The force exerted on bars at the column faces causes the bond force to be dispensed by one of the top beam bars.

$$
\text { Bond Force }=\frac{\Pi \mathrm{d} 2}{4}\left(\mathrm{fy}+\mathrm{f}^{\prime} \mathrm{s}\right)
$$

where $\mathrm{f}^{\prime} \mathrm{s}$ is the compression steel stress at the far face of the joint, fy is the yield stress of steel, and $\mathrm{d}$ is the diameter of steel.

\subsection{Corner RC Beam-Column Joint}

The joints are usually situated near the roof level in movement-resistant RC structures. Suppose these joints are simply intended for gravity loads and are built according to pre-seismic regulations. In that case, they may sustain significant harm during seismic events because of insufficient shear strength in the corner beam-column junction [10,33,34]. Internal forces created at corner joints may induce joint failure before the beam or columnwhichever is weaker-reaches its maximum strength. In earthquake-prone nations such as Japan, Mexico, and China, several approaches for repairing and strengthening corner beam-column joints that earthquakes have damaged have been documented [35].

Only the following requirements may be expected to provide appropriate strength for the corner joint [35]:

i. Around the corner, the tension steel is persistent, i.e., there is no lapping in the joint;

ii. The tension bars have to be curved into a radius that prevents the bars from bending or breaking. Nominal transverse bars are placed beneath the bent bars;

iii. Only a certain quantity of tension reinforcement is allowed [32].

$$
\rho \leq 6 \sqrt{ } \mathrm{f}^{\prime}{ }_{\mathrm{c}} / \mathrm{f}_{\mathrm{y}}
$$

The stresses are measured in pounds per square inch (psi).

\section{Detailing Recommendations for Joints}

The below suggestions are provided in regard to the need for anchorage, confinement, and shear inside the core of joints in earthquake-resistant structures [22]:

i. Anchorage: Due to loss of bond at the inner face of an exterior joint, the development length of the beam reinforcement should be computed from the beginning of the $90^{\circ}$ bend, rather than the face of the column. In wide columns, any portion of the beam bars within the outer third of the column could be considered for the computed development length. For shallow columns, the use of stub beams will be imperative. A large-diameter bearing bar fitted along the $90^{\circ}$ bend of the beam bars should be beneficial in distributing bearing stresses. In deep columns, and whenever straight beam bars are preferred, mechanical anchorage could be advantageous. Joint ties should be so arranged that the critical outer-column bars and the bent-down portions of the bars are held against the core of the joint; 
ii. Shear Strength: When the computed axial compression on the column is small, the contribution of the concrete shear resistance should be ignored, and shear reinforcement for the entire joint-shearing force should be provided. In exterior joints, only the ties that are situated in the outer two-thirds of the length of the potential diagonal failure crack, which runs from corner to corner of the joint, should be considered to be effective. The joint shear to be carried by the ties is calculated as:

$$
\mathrm{A}_{\mathrm{v}}=\frac{1.5 \mathrm{VsS}}{\mathrm{dFy}}
$$

where Vs = joint shear carried by the ties, $A_{V}=$ the total area of tie legs in a pair that makes up one layer of shear reinforcement, and $d=$ the beam's effective depth. For preventing the excessive diagonal compression of core concrete, an upper bound for joint shear, usually stated as a nominal shearing force, must be imposed. The value between $10 \sqrt{ } \mathrm{f}^{\prime}{ }_{\mathrm{C}}$ and $11.5 \sqrt{ } \mathrm{f}^{\prime}{ }_{\mathrm{C}}$ (psi) is recommended for beams;

iii. Confinement: Horizontal tie legs are ineffectual for providing constraint against the concrete core volumetric expansion, while shear reinforcement restricts only the joint's corner regions. As a result, extra confining bars at right angles to the shear reinforcement are required. The distance between these bars should not exceed $150 \mathrm{~mm}$.

The IS 13920:1993 (Ductile Detailing) [22] gives the following provisions:

i. Cl-7.4.1 Special confining reinforcement $\left(l_{0}\right)$ (unless shear strength considerations demand a larger amount of transverse reinforcement) should be provided across a span of every joint face, towards the mid-span, and on each side of any area where flexural yielding may occur owing to earthquake pressures. The length ' $1_{0}$ ' should not be less than (a) the member's greater lateral dimension at the section where yielding occurs, (b) $1 / 6$ of the member's clear span, and (c) $450 \mathrm{~mm}$;

ii. $\quad \mathrm{Cl}-8.1$ Unless the joint is confined, the special confining reinforcement necessary at the column end must also be carried through the joint;

iii. Cl-8.2 A connection with beams framing all vertical sides, with each beam having a width of at least $3 / 4$ of the column width, may be given half of the special restricting reinforcement needed at the column's end. The hoops' spacing shall not be more than $150 \mathrm{~mm}$;

iv. In the joint region, diagonal cracking and concrete crushing can be managed by providing large column dimensions and densely packed closed-loop steel ties surrounding the column bars. The ties help resist the shear stress and hold the concrete in the joint, hence preventing concrete cracking and crushing;

v. The transverse loop should continue around the joint region around the column bars. This is cultivated by setting up the instance of all bar supports (both longitudinal bars and stirrups) on top of the shaft formwork at that level and lower into the case;

vi. The building columns in seismic zones III, IV, and V are to be at least 300-mm wide in each direction of the cross-section when the column support beams are longer than $5 \mathrm{~m}$ or when these columns are taller than $4 \mathrm{~m}$ between floors;

vii. A piece of the top pillar bar is consolidated in the segment that is projected up to the soffit of the bar, and a piece of it overhangs in segments with short widths and huge-breadth shaft bars;

viii. Beam bars may not reach past the soffit of the pillar if the section width is extensive;

ix. Interior joints need the top and base bars to go through the intersection without being cut, and these bars should be set inside the section bars without any twists;

x. The American Concrete Institute suggests a segment width that is no less than multiple times the distance across the longest longitudinal bar in the adjoining pillar. 


\section{Experimental Program}

Interior and corner beam-column joint specimens were divided into two groups: one with changed reinforcing techniques and another without. For both reinforcement frameworks, the specimens were cast with reinforcement details according to IS 456:2000 [36], including extra diagonal cross-bracing reinforcement at the two faces of the joints for joint confinement, in accordance with the reinforcement category.

\section{Details of Specimens}

The beam and column dimensions at the corner and interior beam-column joints were similar. The columns were $300-\mathrm{mm}$ deep and $400-\mathrm{mm}$ broad, while the beams were $400-\mathrm{mm}$ deep and 300-mm wide. The beam's span was $3000 \mathrm{~mm}$, while the column's height was $3500 \mathrm{~mm}$. Figure 1 shows the inner beam-column joint reinforcement detailing without changed reinforcement techniques, whereas Figure 2a,b shows the interior beam-column joint reinforcement detailing with modified reinforcement techniques at the joint location. The concrete mix consisted of ordinary Portland cement ( 43 grade), sand passing through a $4.75-\mathrm{mm}$ IS sieve, and coarse aggregate ranging in size from 10 to $18 \mathrm{~mm}$. The concrete cube's compressive strength after 28 days was $25 \mathrm{~N} / \mathrm{mm}^{2}$. The main reinforcement was made of steel bars with a yield stress of $415 \mathrm{~N} / \mathrm{mm}^{2}$. To account for the pull-out force, the longitudinal beam bars and cross-bracing bars were given enough development lengths, as required by the code. Inside a steel mold, the specimens were cast horizontally.

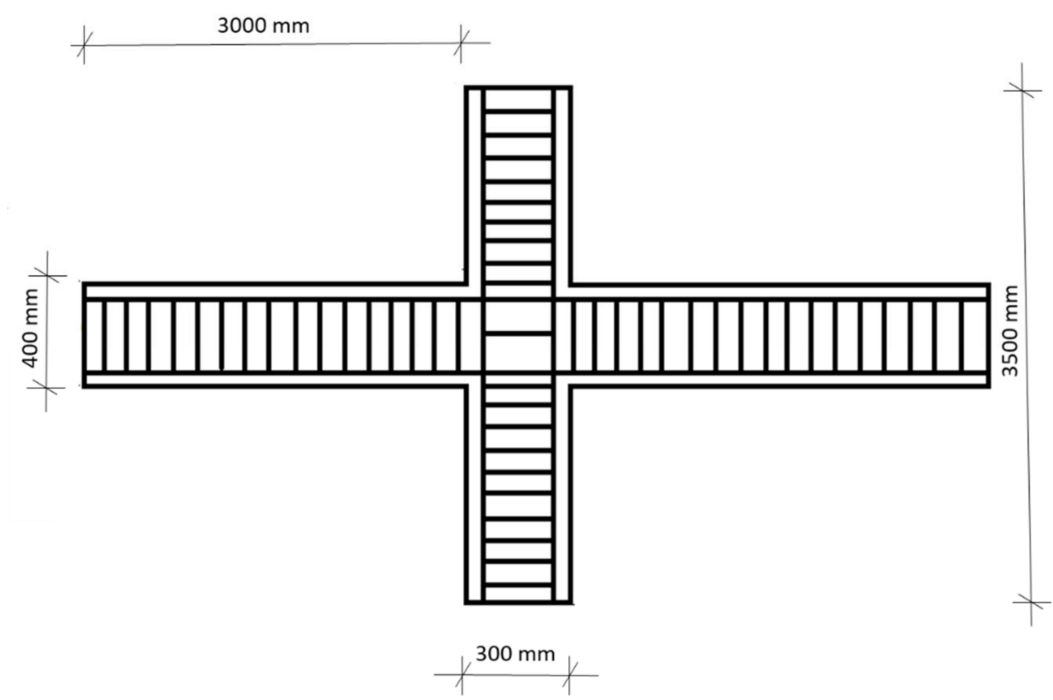

Figure 1. Reinforcement details of controlled specimens.

All of the specimens were put through their paces with a constant axial load and cyclic loading at the beam's end, as shown in Figure 2c. To duplicate the gravity force on the column, a $0-500-\mathrm{kN}$ hydraulic jack was attached vertically to the loading frame and applied a constant column axial load, as shown in Figure $2 \mathrm{~d}$. The external hinge support was attached to one end of the column and anchored to the strong reaction floor, while the other end was restrained laterally by roller support. To apply reverse cyclic loading, two 200-kN hydraulic jacks were employed, one connected to the loading frame at the top and the other to the strong reaction floor. At a distance of $50 \mathrm{~mm}$ from the free end of the beam section of the assembly, the cyclic load was applied. In a load-controlled test, the specimen was exposed to an increasing cyclic load until failure. The load increment was set at $1.962 \mathrm{kN}$. The specimens were equipped with a linear variable differential transformer (LVDT) with a least count of $0.1 \mathrm{~mm}$ to measure the deflection at the loading point [10]. Figures 1 and 2a,b illustrate the schematic diagrams of the controlled and reinforced specimens, respectively. 


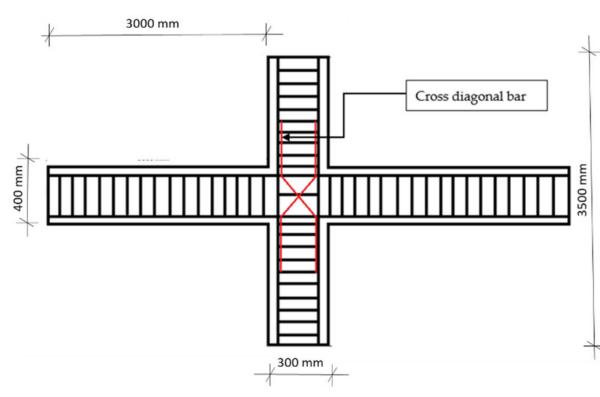

(a)

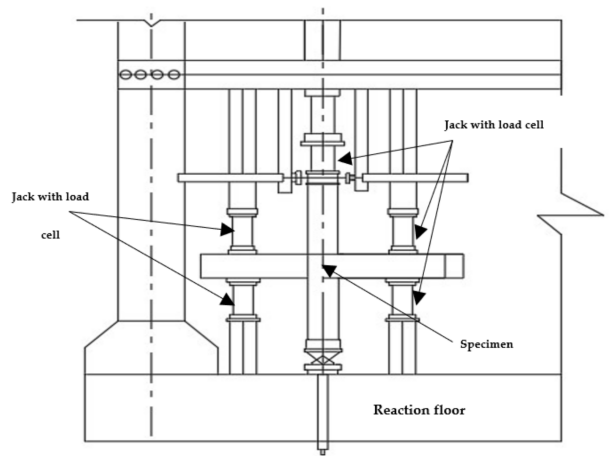

(c)

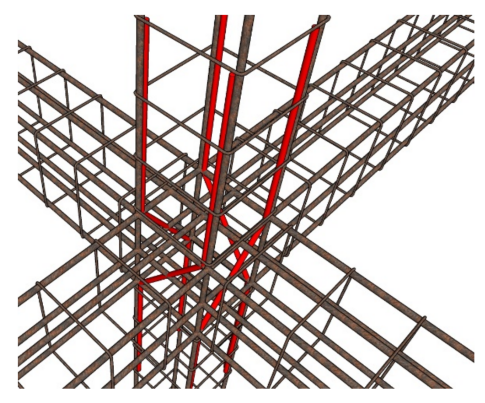

(b)

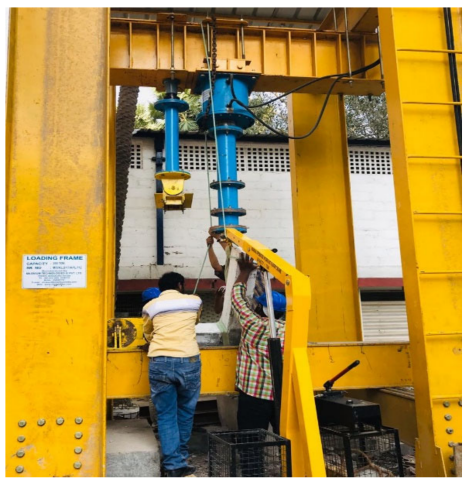

(d)

Figure 2. (a) Schematic diagram of strengthened specimens; (b) reinforcement detailing of strengthened specimens; (c) schematic diagram of test set-up; (d) specimens loading.

\section{Numerical Modeling and Analysis of Beam-Column Joints}

In order to appropriately replicate the tested joint sub-assemblies, symmetry boundary conditions are used. Solid 65, Solid 45, and Link8 elements were used to model the beamcolumn junction. The concrete was modeled with the Solid 65 element, while the hinge support at the base was modeled with the Solid 45 element. There are eight nodes in these elements, each with three degrees of freedom-translations in the nodal $\mathrm{x}, \mathrm{y}$, and $\mathrm{z}$ directions. The reinforcement was modeled using the Link8 element. There are two nodes in this three-dimensional spar element, each with three degrees of freedom-translations in the nodal $\mathrm{x}, \mathrm{y}$, and $\mathrm{z}$ directions. For this, the finite-element software ANSYS Workbench V12 was employed [37]. Following that, each material's element specifics are introduced in Tables 1 and 2. The major goal is to stiffen the column to emulate the beam-column junction behavior on the beam under cyclic loads. The finite-element method [30] converts partial differential equations into a series of algebraic linear equations:

$$
[\mathrm{K}]\{\mathrm{q}\}=\{\mathrm{F}\},
$$

where $\mathrm{K}=$ stiffness matrix, $\mathrm{q}=$ the nodal displacement vector, and $\mathrm{F}=$ the nodal force vector.

Table 1. Concrete characteristics.

\begin{tabular}{cccc}
\hline $\begin{array}{c}\text { Uniaxial Tensile } \\
\text { Strength (MPa) }\end{array}$ & $\begin{array}{c}\text { Poisson's Ratio } \\
\text { Value }\end{array}$ & $\begin{array}{c}\text { Ultimate Uniaxial } \\
\text { Compressive Strength (Mpa) }\end{array}$ & $\begin{array}{c}\text { Modulus of } \\
\text { Elasticity (Mpa) }\end{array}$ \\
\hline $0.62 \sqrt{ } \mathrm{f}_{\mathrm{c}}$ & 0.2 & 25 & $5000 \sqrt{ } \mathrm{f}_{\mathrm{c}}$ \\
\hline
\end{tabular}

Table 2. Steel characteristics.

\begin{tabular}{cccc}
\hline $\begin{array}{c}\text { Poisson's Ratio } \\
\text { Value }\end{array}$ & $\begin{array}{c}\text { Transverse Steel } \\
\text { Yielding Stress (Mpa) }\end{array}$ & $\begin{array}{c}\text { Longitudinal Steel } \\
\text { Yielding Stress (Mpa) }\end{array}$ & $\begin{array}{c}\text { Modulus of } \\
\text { Elasticity (Mpa) }\end{array}$ \\
\hline 0.3 & 250 & 415 & 200,000 \\
\hline
\end{tabular}


Concrete: An 8-noded solid element, or Solid 65 element, is used to simulate the concrete [38]. Every node in the corner and inner beam-column junction solid elements have translations in the nodal planes $\mathrm{x}, \mathrm{y}$, and $\mathrm{z}$ with a degree of freedom of three. Therefore, plastic deformation, three-dimensional cracking, and crushing are all possible with this element. The concrete's characteristics are shown in Table 1, below.

Steel: Standard Grade Fe $415 \mathrm{Mpa}$ steel is used for the steel reinforcement in both the corner and interior beam-column connections. A Link8 component characterizes the steel reinforcement. This element necessitates the use of two nodes. Every node has a degree of freedom of three that correlates to the translations of the node's $\mathrm{x}, \mathrm{y}$, and $\mathrm{z}$ coordinates. Table 2 shows the characteristics of the steel.

In the engineering data utilized for the FE analysis of corner and interior joints, the geometric properties were as stated in Table 3 .

Table 3. Geometric properties of the corner and interior joints.

\begin{tabular}{cccc}
\hline $\begin{array}{c}\text { Parametric Specifications } \\
\text { of Beam }\end{array}$ & $\begin{array}{c}\text { Measurements } \\
(\mathbf{m m})\end{array}$ & $\begin{array}{c}\text { Parametric Specifications } \\
\text { of Column }\end{array}$ & $\begin{array}{c}\text { Measurements } \\
(\mathbf{m m})\end{array}$ \\
\hline Concrete cover & 30 & Concrete cover & 30 \\
Span & 3000 & Column's depth & 300 \\
Depth & 400 & Width of column & 300 \\
Width & 300 & Column height & 3500 \\
Steel at bottom & $4-10$ & Floor-to-floor height & 3250 \\
Steel at top & $4-10$ & Longitudinal steel & $4-12$ \\
Diameter of Transverse steel & 6 & Diameter of Transverse steel & 6 \\
Spacing of Transverse steel & 220 & Spacing of Transverse steel & 200 \\
\hline
\end{tabular}

ANSYS software's geometry tools model the interior and corner beam-column junction specimens as a 3D model. Figures $3 \mathrm{a}, \mathrm{b}$ and $4 \mathrm{a}, \mathrm{b}$ demonstrate the developed geometry as well as usual reinforcing (with steel) details of regulated and strengthened specimens, respectively, where Figure $3 \mathrm{a}, \mathrm{b}$ represents an interior joint and Figure $4 \mathrm{a}, \mathrm{b}$ represents a corner joint. In an ideal circumstance, the true binding force between reinforcing steel and concrete needs to be envisioned. However, a perfect bond between the two materials is postulated in this investigation. The Link8 component symbolizes the reinforcing steel bars connected to the nodes of each adjacent solid component of concrete to provide a consistent bonding; hence, both the materials contribute to the same node. A square mesh is used to obtain good results from the Solid65 element. As a result, the meshing is configured to produce square or rectangular mesh segments. This ensures that the dimensions of the components in the concrete support are compatible with the components and nodes in the model's concrete sections. The specimen is modeled with a square concrete element and a mesh size of $50 \mathrm{~mm}[35]$.

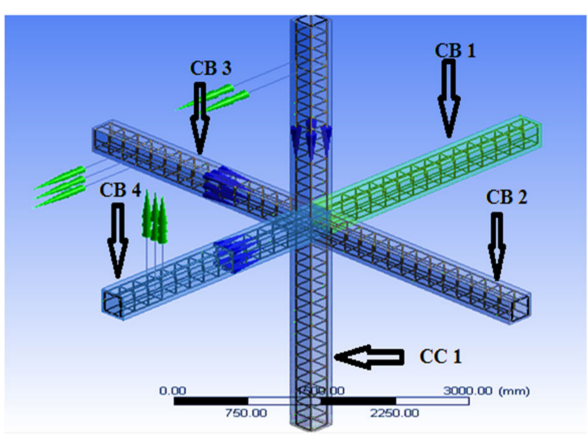

(a)

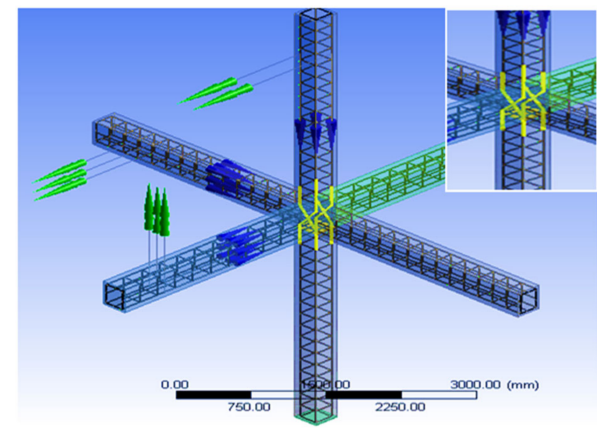

(b)

Figure 3. Geometric model and detail of reinforcement for interior joint; (a) controlled specimen, (b) strengthened specimen. 


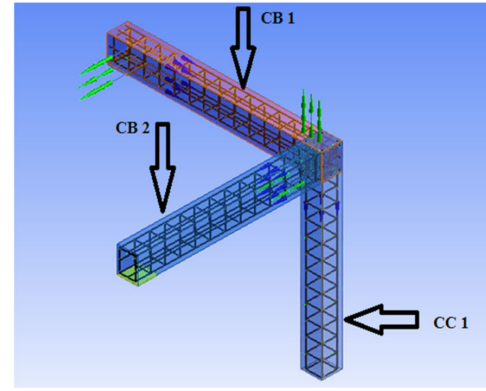

(a)

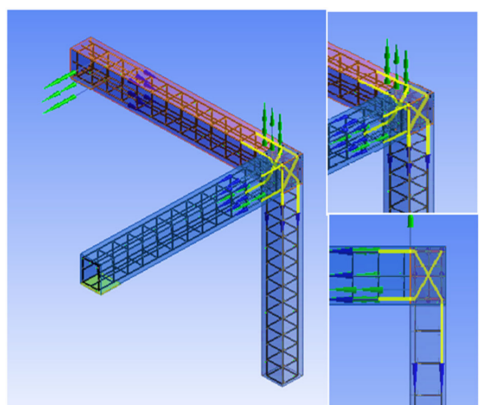

(b)

Figure 4. Geometric model and detail of reinforcement for corner joint; (a) controlled specimen, (b) strengthened specimen.

\section{Results Obtained by Numerical Modeling}

FE analysis findings for controlled and strengthened specimens were obtained utilizing ANSYS Workbench [37]. The specimens were subjected to cyclic loads ranging between $0-500 \mathrm{kN}$. For both specimens, maximum strain, shear stress, and total deformation are compared. According to the results, the above three interior and corner beam-column junction parameters are managed with improved reinforcing methods at the joint region (Tables 4 and 5). At the joint, the deformation that occurred in the controlled specimen is reduced in a strengthened specimen (Figure $5 b$ ), and the same is also transmitted to the CB1 beam of the corner beam-column junction, according to the controlled specimen's overall deformation model (Figure 5a).

Table 4. Analyzed findings of interior beam-column joint.

\begin{tabular}{cccc}
\hline Measured Parameter & $\begin{array}{c}\text { Highest Value with } \\
\text { No MRT }\end{array}$ & $\begin{array}{c}\text { Highest Value Using } \\
\text { MRT }\end{array}$ & Variation in \% \\
\hline Overall deformation $(\mathrm{mm})$ & 0.87369 & 0.09106 & 89.5 \\
Maximum Shear stress $(\mathrm{MPa})$ & 19.92 & 9.0418 & 79.3 \\
Maximum Shear strain $(\mathrm{mm} / \mathrm{mm})$ & 0.0065 & 0.00062 & 90.4 \\
\hline
\end{tabular}

Table 5. Post analysis findings of corner beam-column joint.

\begin{tabular}{cccc}
\hline Measured Parameter & $\begin{array}{c}\text { Highest Value with } \\
\text { No MRT }\end{array}$ & $\begin{array}{c}\text { Highest Value Using } \\
\text { MRT }\end{array}$ & Variation in \% \\
\hline Overall deformation (mm) & 5.7922 & 0.13358 & 97.7 \\
Maximum shear stress (MPa) & 52.112 & 10.808 & 79.3 \\
Maximum shear strain (mm/mm) & 0.0009396 & 0.0003444 & 63.3 \\
\hline
\end{tabular}

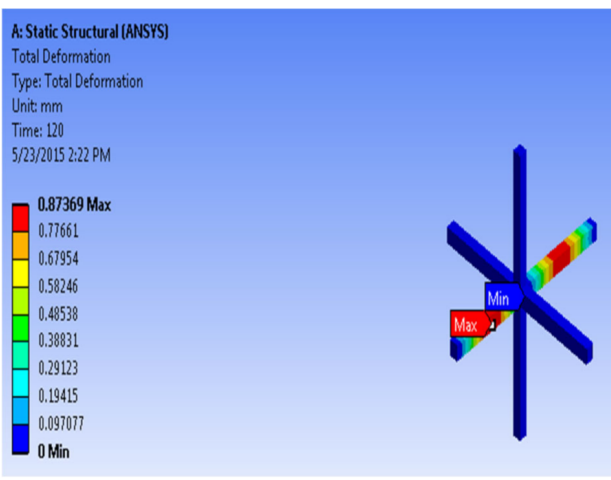

(a)

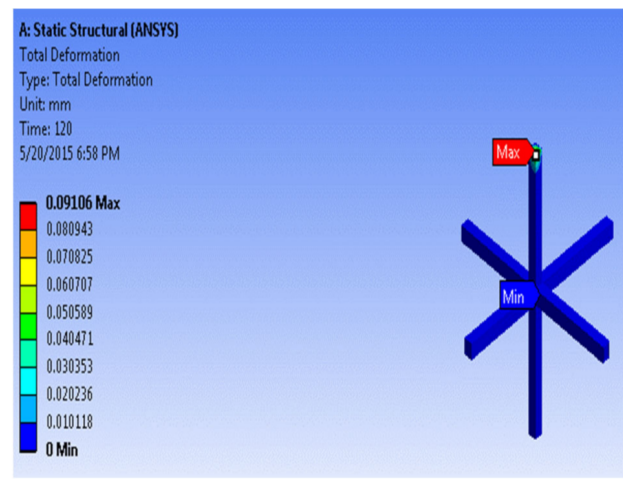

(b)

Figure 5. Total deformation for (a) control specimen with four beams (ICS) and (b) strengthened specimen with four beams (ISS). 
From the total deformation model of the control specimen of an interior joint (ICS) (Figure 5a), it is observed that the minimum deformation is in the column and the maximum deformation is in the beam with no modified reinforcement techniques. Furthermore, the total deformation after strengthening with the modified reinforcement technique (ISS) was controlled, as shown in Figure 5b.

From Figure $6 \mathrm{a}$, the maximum shear stress for the control specimen (i.e., without MRT) is observed to be equal in all sections of the interior joint. On the other hand, for the strengthened specimen, as shown in Figure $6 \mathrm{~b}$, it is found that there is minimum stress in the column and maximum stress in the beam; the stress in the beam-column joint was also controlled using the MRT technique.

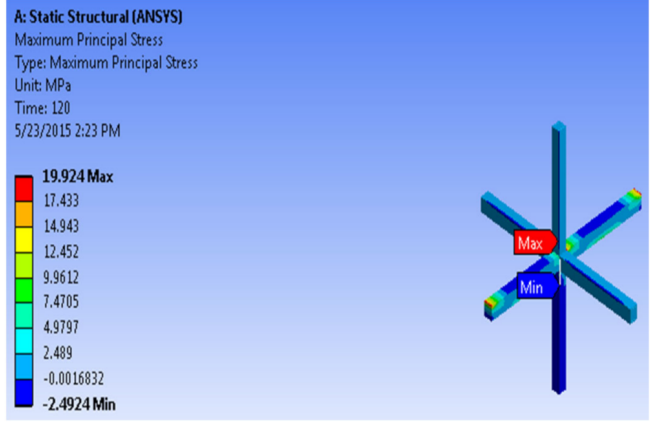

(a)

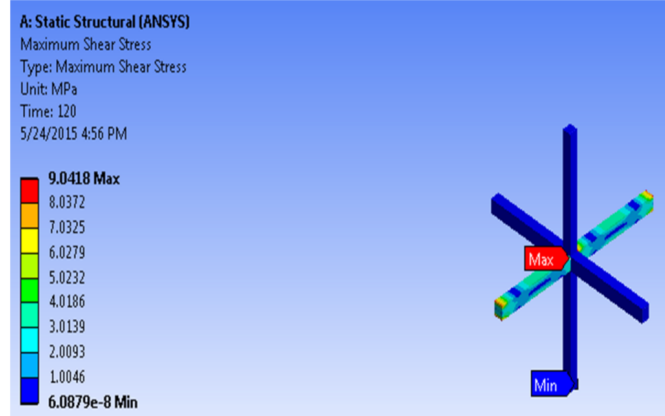

(b)

Figure 6. Maximum Principal stress in the interior joint; (a) control specimen with four beams (ICS) and (b) strengthened specimen with four beams (ISS).

From Figure 7a, the maximum principal strain for the control specimen on the interior beam-column junction (without MRT) is observed at the center of the column; while the minimum strain at the bottom support of the column is the strengthened specimen from Figure $7 \mathrm{~b}$, it is observed that the maximum principal strain for strengthening the specimen (with MRT) is at the support of the beam and the minimum principal strain is in the column. The strain in the joint is controlled by introducing MRT at the joint.

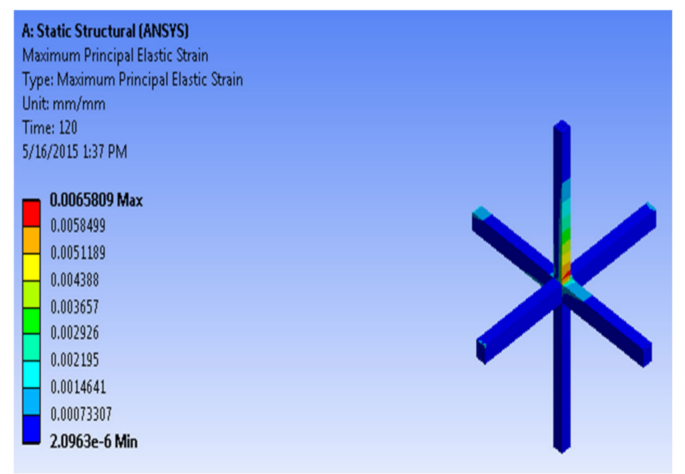

(a)

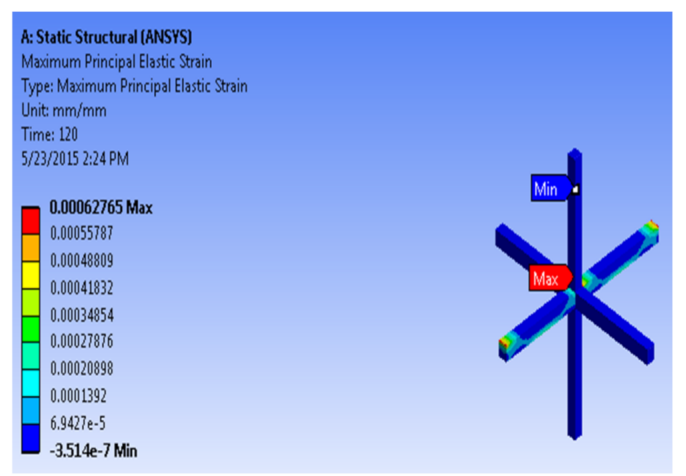

(b)

Figure 7. Maximum principal elastic strain in the interior joint for (a) the control specimen with four beams (ICS) and (b) the strengthened specimen with four beams (ISS).

Figure 8a shows that the highest deformation is at the corner joint and the minimum deformation is at the bottom support of the column for the controlled specimen. Figure $8 \mathrm{~b}$ shows that the total deformation in the corner joint is controlled, compared to the controlled specimen after being strengthened with the modified reinforcement technique. 


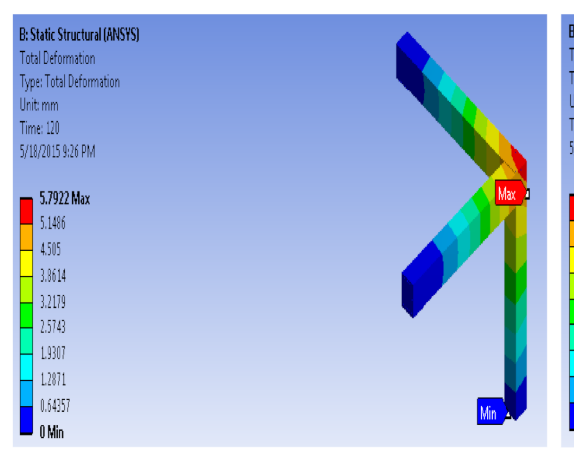

(a)

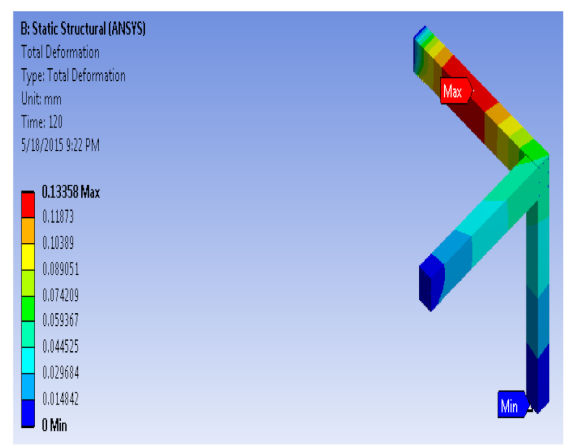

(b)

Figure 8. Total deformation in the corner joint for (a) the control specimen (CCS) and (b) the strengthened specimen (CSS).

From Figure $9 \mathrm{a}$, it is observed that the maximum principal stress for the control specimen in the corner joint (without MRT) is at the support of the beam, and for the strengthened specimen from Figure 9b, the maximum and minimum stress is found at the support of the beam. It can also be observed that the stress in the beam-column junction is controlled.

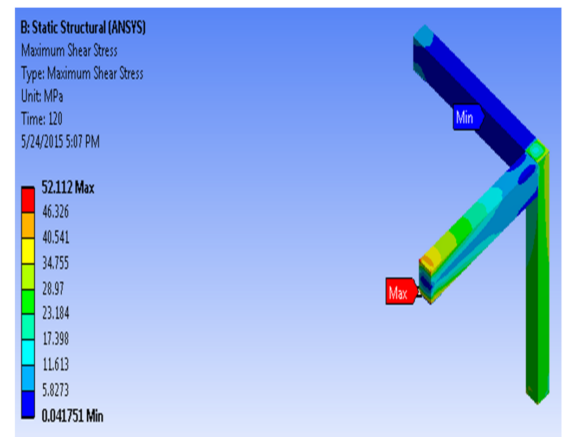

(a)

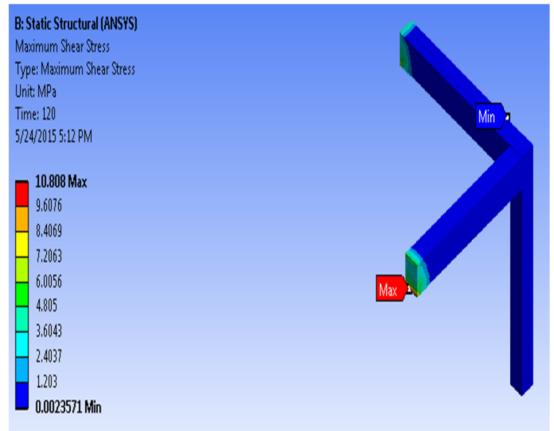

(b)

Figure 9. Maximum shear stress in the corner joint for (a) the control specimen (CCS) and (b) the strengthened specimen (CSS).

In Figure 10a, the maximum shear strain for the control specimen of the corner beamcolumn junction (without MRT) is observed at the support of the beam, while the minimum strain is at the corner joint. For the strengthened specimen, it is found that the strain in the corner joint is controlled by introducing MRT at the joint.

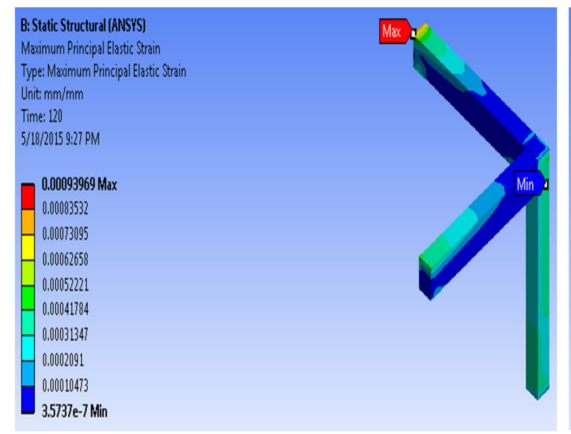

(a)

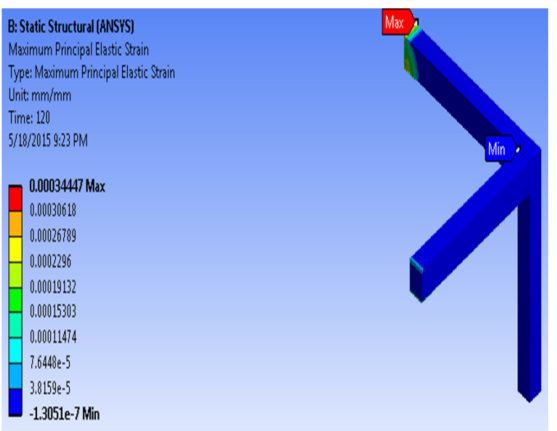

(b)

Figure 10. Maximum principal strain in the corner joint for (a) the control specimen (CCS) and (b) the strengthened specimen (CSS). 


\subsection{Validation of Results}

The results obtained through finite-element analysis for interior and corner beamcolumn joints were validated with experimental results in load-deformation behavior, as shown in Figures 11a,b and 12a,b, for the control and strengthened specimens. The load-deformation behavior found in the simulation was very similar to the findings of the experimental studies, with the variation of load ranging from $3 \%$ to $5 \%$.

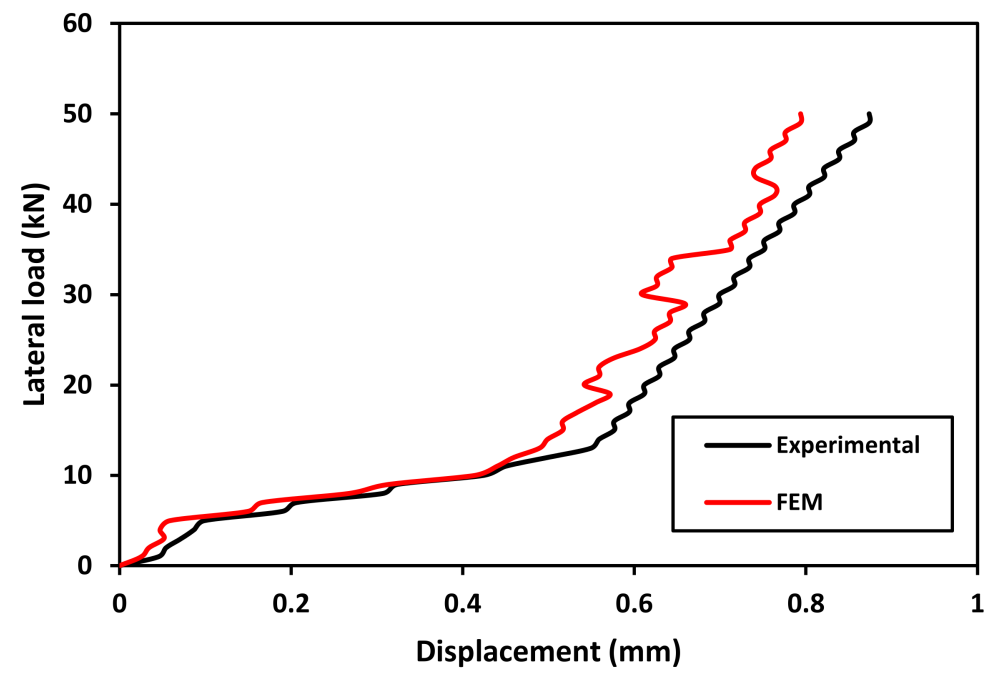

(a)

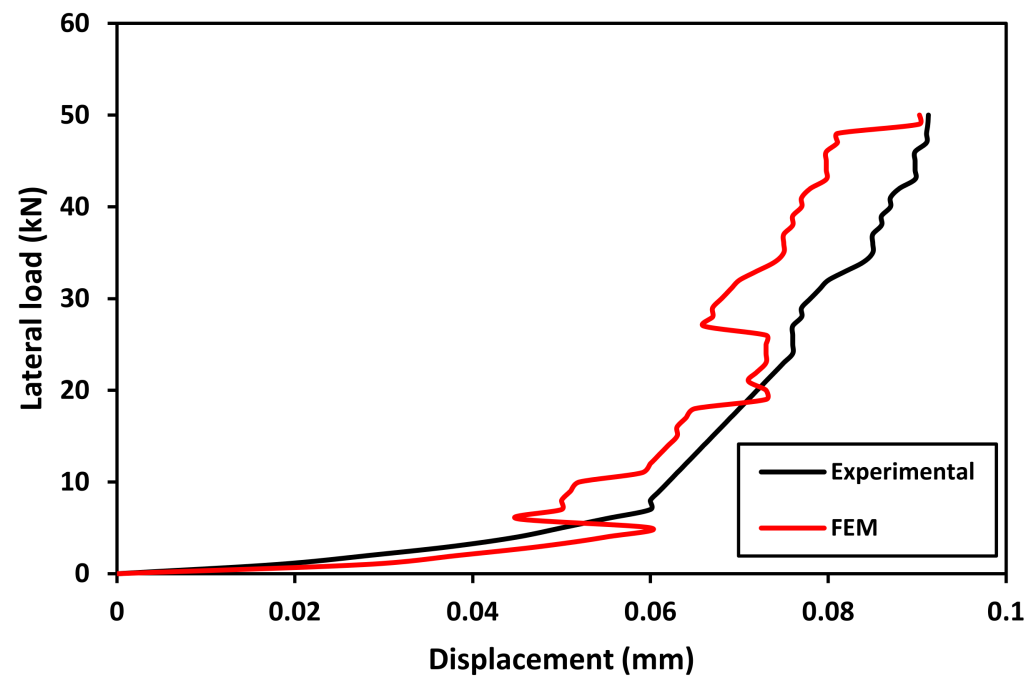

(b)

Figure 11. (a) Load-displacement response of controlled specimen (ICS). (b) Load-displacement response of strengthened specimens (ISS).

\subsection{Load-Displacement Behaviour for Beam-Column Joints}

In Figures 11a and 12a the load-displacement behavior curves are used to compare the results obtained through experimental and finite-element analysis of controlled specimens. The comparison of strengthened specimens of interior and corner beam-column joints are shown in Figures $11 \mathrm{~b}$ and $12 \mathrm{~b}$, respectively. The results obtained through finite-element analysis were in great concurrence with the experimental results. The load-deformation behavior shown in the simulation was extremely close to that observed in experimental studies, with load variations ranging from 3\% to $5 \%$. Compared to the controlled specimens, 
the strengthened specimens displayed elastic behavior at the beginning stage in both the cases (interior and corner joint). Analysis determines the load-displacement characteristics indicated the better performance of strengthened specimens featuring cross-inclined reinforcement at the junction, which resulted in overall managed deformation and raised the ultimate loading capability compared to the controlled specimen in both types of joints, whether corner or inner.

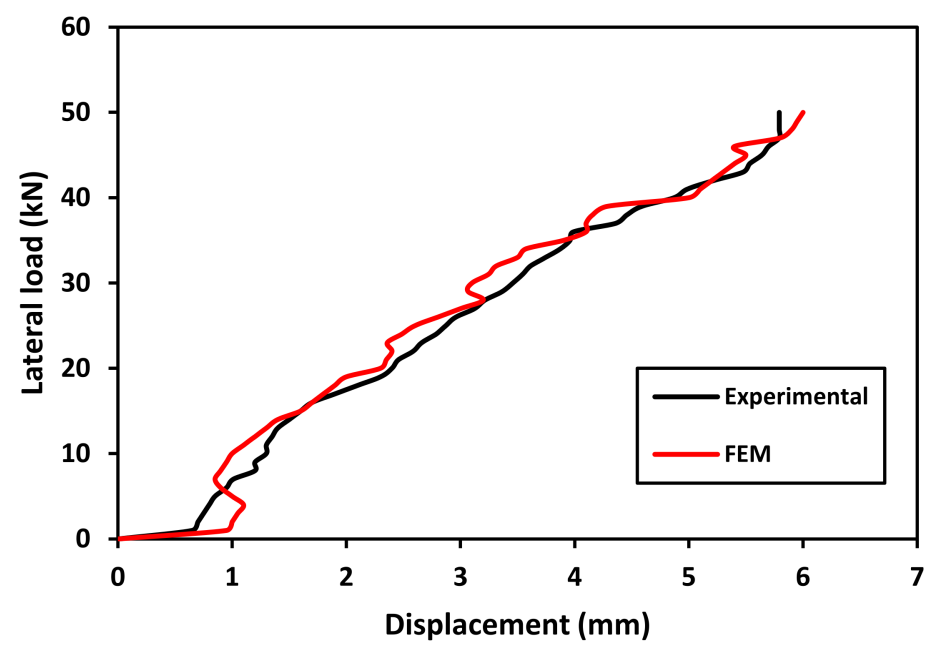

(a)

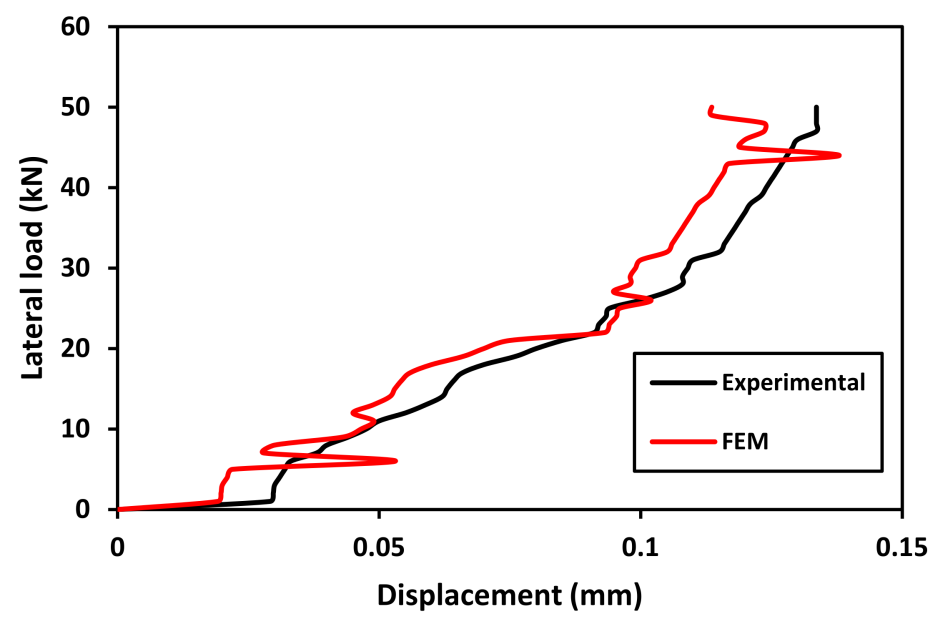

(b)

Figure 12. (a) Load-displacement response of controlled specimen (CCS). (b) Load-displacement response of strengthened specimens (CSS).

Thus, considering the ultimate load-carrying capacities from numerical studies, the specimens with diagonal confining bars (modified reinforcement technique) performed well for both cases of column axial loads. Furthermore, it can be observed that the displacement is more controlled for the ISS and CSS specimens by using cross-inclined bars at the joint than that of the ICS and CCS specimens for both the column axial load cases.

\section{Results and Discussions}

Though the reinforcement detailing of structures conform to the general construction code of practice, it may not adhere to modern seismic provisions. Current seismic code specifications for reinforced concrete-framed constructions are frequently deemed unrealistic by structural experts. They lose structural efficiency when a beam-column 
junction is subjected to significant lateral stresses, such as strong winds, earthquakes, or explosions. To satisfy the requirements of strength, stiffness, and ductility under cyclic loading, significant percentages of transverse hoops in the cores of joints are required in these locations. Provisions with a high percentage of hoops generate steel congestion, which causes construction difficulties.

On three fronts, researchers are looking into both kinds of beam-column joints (corner and interior).

The factors influencing the behavior of cyclically loaded corner and interior beamcolumn junctions are examined in the first approach. IS 456:2000 [36] was used to detail the joints. This method measures the maximum principal elastic strain and shear stress and overall deformation of controlled specimens (without MRT) under cyclic loading.

The controlled specimens are strengthened at the joint area in the second approach by using a modified reinforcement method (MRT) on both sides of the column, having a 12-mm diameter crossbar of length $450 \mathrm{~mm}$ (as per IS 456:2000) [36] installed. Testing of the joints under the same cyclic loads as the controlled specimens was performed. According to the findings, the improved reinforcing approach boosted the joint's shear resistance capability while simultaneously limiting overall deformation.

Comparison of all the FEM findings of both the control and strengthened specimens of corner and interior beam-column junctions is completed in the third approach. The cyclic response of the corner, as well as the inner beam-column connection, is found to be improved by utilizing updated reinforcing techniques concerning the maximum principal elastic strain and stress as well as overall deformation. The findings are compared using the lateral-loading vs. lateral-displacement curve, loading vs. deflection hysteretic curve, and deflection time history curve along with shear stress vs. load-cycle curve. The findings of the examination of the corner and interior joints are displayed in Table 6.

Table 6. Comparison of specimens with and without MRT.

\begin{tabular}{cccc}
\hline Specimen ID & $\begin{array}{c}\text { Overall Deformation } \\
(\mathbf{m m})\end{array}$ & $\begin{array}{c}\text { Maximum Shear Stress } \\
\mathbf{( M p a )}\end{array}$ & $\begin{array}{c}\text { Maximum Principal Elastic } \\
\text { Strain } \mathbf{( m m} / \mathbf{m m})\end{array}$ \\
\hline CS4 & 0.873 & 19.92 & 0.00062 \\
SS4 & 0.091 & 9.924 & 0.00018 \\
CS5 & 5.7922 & 52.11 & 0.00093 \\
SS5 & 0.1336 & 10.81 & 0.00034 \\
\hline
\end{tabular}

\subsection{Hysteretic Behavior of Corner and Interior Beam-Column Junctions}

In consideration of shear capacity and deformation capability, the stress-strain behavior of both beam-column junctions, i.e., corner and interior, is investigated. Hysteretic curves in Figure 13a-d depicts load-displacement equations for fixed and strengthened specimens. The overall deformation in controlled specimens of both the interior and corner junctions (ICS and CCS) is higher than strengthened specimens (ISS and CSS). The loading capacities of ISS and CSS are significantly higher than ICS and CCS, as per the findings of the hysteretic analysis. The ductility is increased without compromising the stiffness. In general, specimens with diagonal crossbars perform better than their conventionally detailed counterparts.

\subsection{Shear Stress vs. Loading Cycle Behavior of Joints}

The ductility of specimens reinforced using the cross-inclined bar, as per IS 456:2000, at the corner and interior beam-column junctions outperforms the regulated specimen with no cross-inclined reinforcement. The addition of cross-inclined reinforcement boosted both the ultimate load-bearing capacity and ductility of the interior as well as of the corner junction in both load circumstances (downward and upward), according to the numerical investigation. The inclusion of slanted bars creates a new shear-transmission mechanism. The corner and interior beam-column junctions using the modified reinforcement method (MRT) have better strength, as shown in Figure 14a,b. 


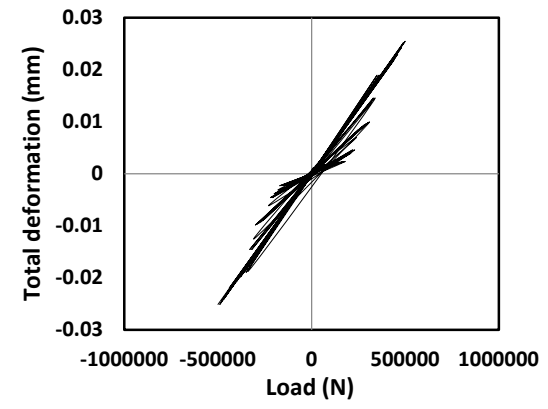

(a)

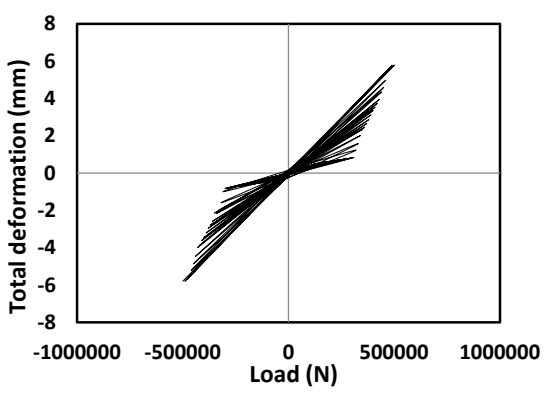

(c)

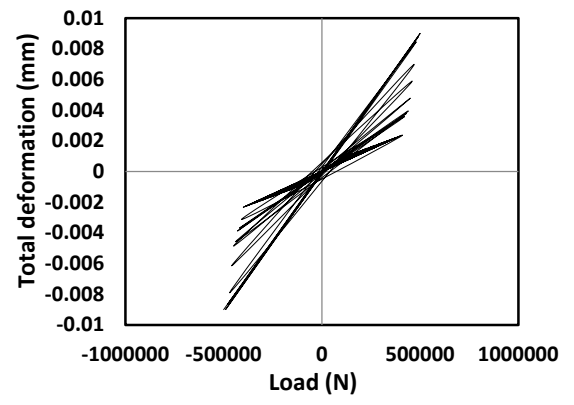

(b)

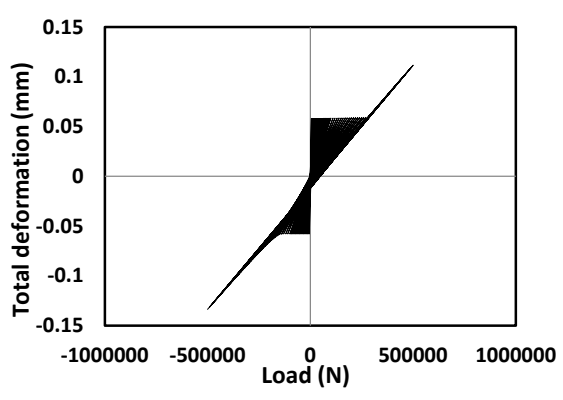

(d)

Figure 13. (a) Load vs. total deformation hysteretic graph for the controlled specimen (ICS) (without MRT) and (b) the strengthened specimen (ISS) (with MRT). (c) Load vs. total deformation graph for the controlled specimen (CCS) (without MRT) and (d) the strengthened specimen (CSS) (with MRT).

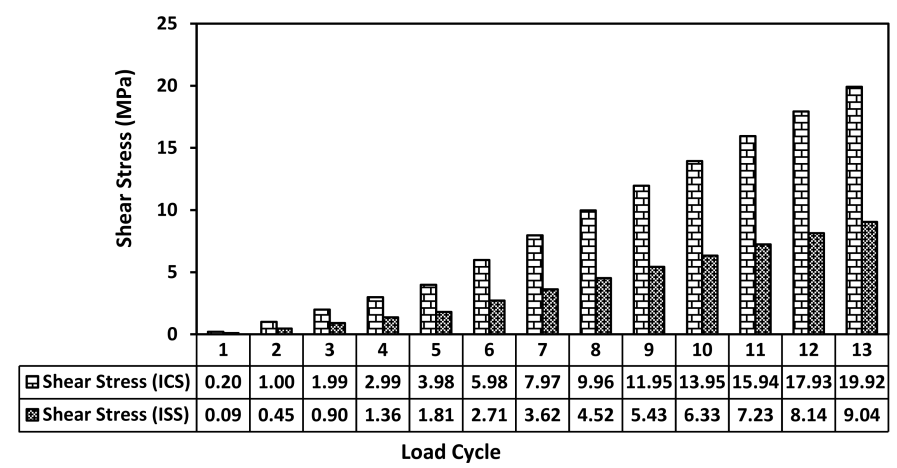

(a)

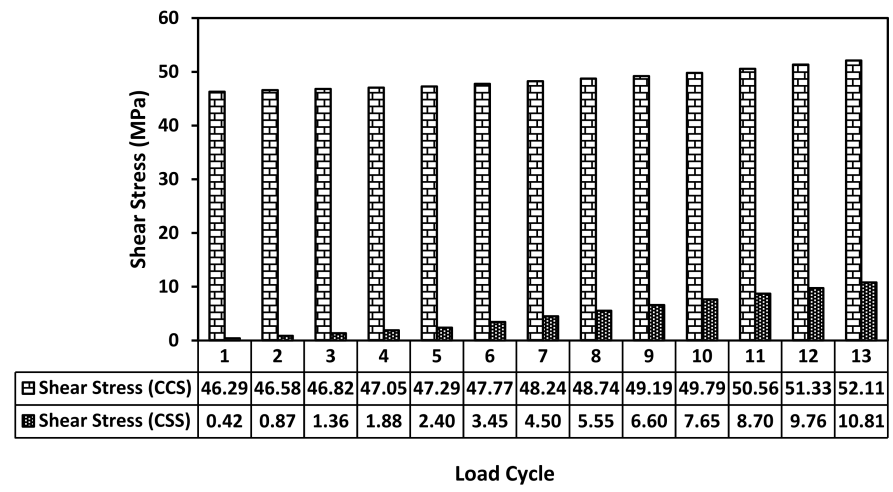

(b)

Figure 14. (a) Shear stress vs. load cycle for the controlled specimen (ICS) and the strengthened specimen (ISS). (b) Shear stress vs. load cycle for the controlled specimen (CCS) and the strengthened specimen (CSS). 


\subsection{Displacement Time History Curve for Beam-Column Joints}

Figures 15a and 16a illustrate the lateral load-displacement time histories curve obtained through numerical analysis for the controlled specimens. Figures $15 \mathrm{~b}$ and $16 \mathrm{~b}$ represent the numerical findings that strengthened the specimen's lateral load-displacement time histories. All of the cycles progressed to the push motion after being started with the pull motion. Adopting cross-inclined bars at the joint location to reinforce beam-column joints offers more strength than the controlled specimen in both cases.

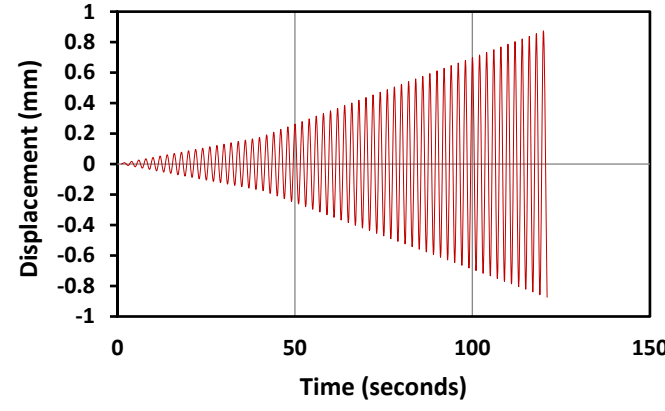

(a)

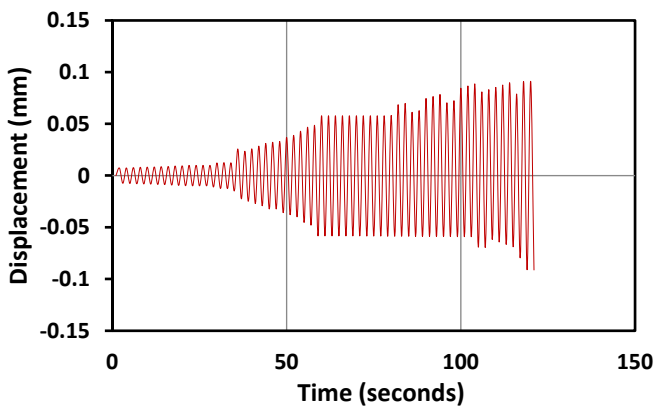

(b)

Figure 15. (a) Displacement time history of the controlled specimen (ICS) and of (b) the strengthened specimen (ISS).

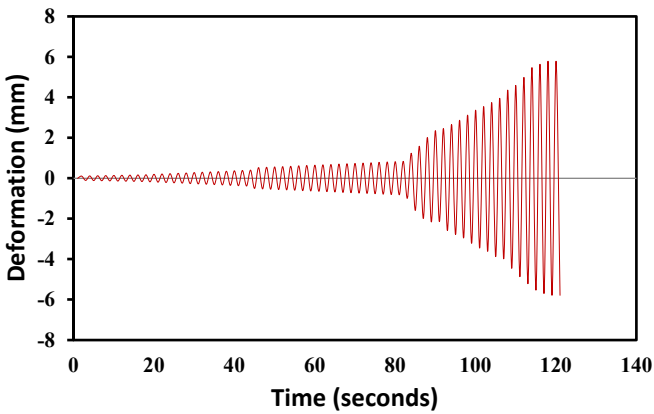

(a)

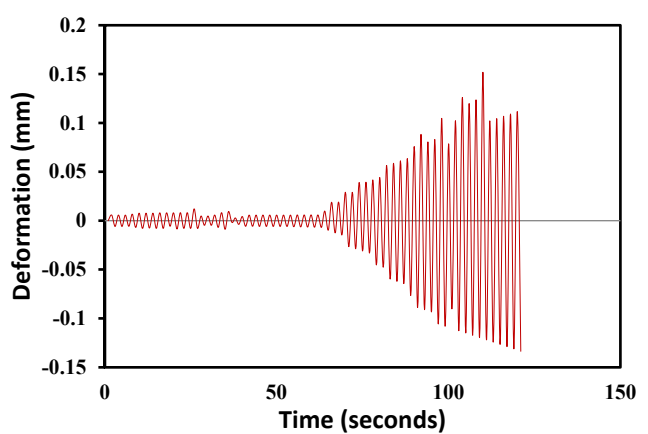

(b)

Figure 16. (a) Displacement time history of the controlled specimen (CCS) and of (b) the strengthened specimen (CSS).

\section{Conclusions}

The behavior of beam-column joints in RC structures is of great importance for the seismic behavior of a whole structure. Hence, the investigation and research in the field is beneficial, and new methods, techniques, and procedures can help achieve a better understanding of the complex behavior of the joints themselves. Strengthening and upgrading such elements can be completed, e.g., by high-strength steel bars [39], steel jacketing [40], cementitious composites [41], FRP ropes [42], self-centering friction haunches [43], etc. The RC beam-column joints can also be predicted by using modern techniques such as machine learning [44]. In this study, the performance of interior and corner beam-column joints were analyzed through an experimental program, and the results obtained through tests were validated using finite-element software ANSYS. Similar studies were performed by Santarsiero [45]. The following findings may be derived:

i. Based on the present research, the most critical parameters influencing joint shear capacity are the stirrups quantity, the aspect ratio of the joint, the beam longitudinal reinforcement anchorage, and the compressive strength of concrete; 
ii. The results obtained through the experimental studies were validated with numerical analysis in terms of load-deformation behavior, and the numerical results were in great concurrence with the experimental data;

iii. The findings of the finite-element model are compared to the controlled and strengthened specimens, and it is discovered that adding diagonal cross bars (modified reinforcing techniques) to beam-column joints exposed to cyclic loads enhances their performance more than using a controlled specimen in both interior and corner beam-column joints;

iv. The corner beam-column joint models for the controlled and strengthened specimens are analyzed for similar loadings with different reinforcement arrangements. The larger deformations and stresses, which are reported in the controlled specimen, are reduced in the strengthened specimens after employing modified reinforcement techniques;

v. When the controlled and strengthened specimens for the interior beam-column joint are analyzed, it is found that the maximum stress and deformation caused in the joint are controlled by using additional diagonal cross bars at the joint region;

vi. Modified reinforcement techniques with the diagonal cross bar at the joint region is a viable option for enhancing the shear capacity of beam-column joints. The diagonal cross bars help to create an extra shear-transfer mechanism;

vii. A beam-column junction loses structural efficiency when it is exposed to large lateral stresses, such as high winds. Therefore, against such stresses, the specimens with a diagonal crossbar at the junction work best;

viii. In both upward- and downward-load situations, the introduction of cross-inclined bars at the junction area of a strengthened corner and an interior beam-column junction maximizes the joint's stiffness, enhances its load-carrying capacity, as well as its ductility, according to an improved reinforcing approach.

Author Contributions: Conceptualization: A.K.T., S.S. (Sandeep Singh) and S.S. (Shubham Sharma); methodology: A.K.T., S.S. (Sandeep Singh), J.S.C., R.K., S.S. (Shubham Sharma) and M.S.; formal analysis: A.K.T., S.S. (Sandeep Singh), J.S.C., R.K., S.S. (Shubham Sharma) and M.S.; investigation: A.K.T., S.S. (Sandeep Singh), S.S. (Shubham Sharma) and M.S.; resources: S.S. (Shubham Sharma), S.C., F.A. and M.S.; writing-original draft preparation: A.K.T., S.S. (Sandeep Singh), J.S.C., R.K. and S.S. (Shubham Sharma); writing-review and editing: J.S.C., R.K., S.S. (Shubham Sharma), S.C., F.A. and M.S.; supervision: S.S. (Sandeep Singh), J.S.C., R.K., S.S. (Shubham Sharma) and M.S.; funding acquisition: M.S. and S.S. (Shubham Sharma). All authors have read and agreed to the published version of the manuscript.

Funding: This work receives no external funding.

Institutional Review Board Statement: Not applicable.

Informed Consent Statement: Not applicable.

Data Availability Statement: The data presented in this study are available on request from the corresponding author.

Conflicts of Interest: The authors declare no conflict of interest.
Abbreviations
MRT Modified reinforcement technique
ICS Controlled specimen of interior joint without MRT
CCS Controlled specimen of corner joint without MRT
ISS Strengthened specimen of interior joint with MRT
CSS Strengthened specimen of corner joint with MRT 


\section{References}

1. Bossio, A.; Fabbrocino, F.; Lignola, G.P.; Prota, A.; Manfredi, G. Simplified Model for Strengthening Design of Beam-Column Internal Joints in Reinforced Concrete Frames. Polymers 2015, 7, 1732-1754. [CrossRef]

2. Calvi, G.M.; Magenes, G.; Pampanin, S. Relevance of beam-column joint damage and collapse in rc frame assessment. J. Earthq. Eng. 2002, 6, 75-100. [CrossRef]

3. Park, R. A summary of results of simulated seismic load tests on reinforced concrete beam-column joints, beams and columns with substandard reinforcing details. J. Earthq. Eng. 2002, 6, 147-174. [CrossRef]

4. Alsayed, S.H.; Al-Salloum, Y.A.; Almusallam, T.H.; Siddiqui, N.A. Seismic Response of FRP-Upgraded Exterior RC Beam-Column Joints. J. Compos. Constr. 2010, 14, 195-208. [CrossRef]

5. Alhaddad, M.S.; Siddiqui, N.A.; Abadel, A.A.; Alsayed, S.H. Numerical Investigations on the seismic Behavior of FRP and TRM Upgraded RC Exterior Beam-column Joints. J. Compos. Constr. 2012, 16, 308-321. [CrossRef]

6. Rossetto, T.; Elnashai, A. Derivation of vulnerability functions for European-type RC structures based on observational data. Eng. Struct. 2003, 25, 1241-1263. [CrossRef]

7. Ricci, P.; De Luca, F.; Verderame, G.M. 6th April 2009 L'Aquila earthquake, Italy: Reinforced concrete building performance. Bull. Earthq. Eng. 2010, 9, 285-305. [CrossRef]

8. Pejovic, J.; Stepinac, M.; Serdar, N.; Jevric, M. Improvement of Eurocode 8 Seismic Design Envelope for Bending Moments in RC Walls of High-rise Buildings. J. Earthq. Eng. 2020, 1-25. [CrossRef]

9. Kišiček, T.; Stepinac, M.; Renić, T.; Hafner, I.; Lulić, L. Strengthening of masonry walls with FRP or TRM. J. Croat. Assoc. Civ. Eng. 2020, 72, 937-953. [CrossRef]

10. Bindhu, K.R.; Jaya, K.P. Strength and Behavior of Exterior Beam Column Joints with Diagonal Cross Bracing Bars. Asian J. Civil. Eng. 2010, 11, 397-410.

11. Ramírez-Herrera, M.-T.; Romero, D.; Corona, N.; Nava, H.; Torija, H.; Maguey, F.H. The 23 June 2020 MW 7.4 la crucecita, Oaxaca, Mexico earthquake and tsunami: A rapid response field survey during COVID-19 crisis. Seismol. Res. Lett. 2020, 92, 26-37. [CrossRef]

12. Cetin, K.O.; Mylonakis, G.; Sextos, A.; Stewart, J.P. Reconnaissance of 2020 M 7.0 Samos Island (Aegean Sea) earthquake. Bull. Earthq. Eng. 2021, 1-6. [CrossRef]

13. Stepinac, M.; Lourenço, P.B.; Atalić, J.; Kišiček, T.; Uroš, M.; Baniček, M.; Novak, M.Š. Damage classification of residential buildings in historical downtown after the ML5.5 earthquake in Zagreb, Croatia in 2020. Int. J. Disaster Risk Reduct. 2021, 56, 102140. [CrossRef]

14. Almusallam, T.H.; Al-Salloum, Y.A. Seismic response of interior RC beam-column joints upgraded with FRP sheets. II: Analy-sis and Parametric Study. J. Compos. Constr. 2007, 11, 590-600. [CrossRef]

15. Dabiri, H.; Kaviani, A.; Kheyroddin, A. Influence of reinforcement on the performance of non-seismically detailed RC beamcolumn joints. J. Build. Eng. 2020, 31, 101333. [CrossRef]

16. Dabiri, H.; Kheyroddin, A.; Kaviani, A. A Numerical Study on the Seismic Response of RC Wide Column-Beam Joints. Int. J. Civ. Eng. 2018, 17, 377-395. [CrossRef]

17. Tsonos, A.-D.; Kalogeropoulos, G.; Iakovidis, P.; Bezas, M.-Z.; Koumtzis, M. Seismic Performance of RC Beam-Column Joints Designed According to Older and Modern Codes: An Attempt to Reduce Conventional Reinforcement Using Steel Fiber Reinforced Concrete. Fibers 2021, 9, 45. [CrossRef]

18. Hanif, F.; Kanakubo, T. Shear Performance of Fiber-Reinforced Cementitious Composites Beam-Column Joint Using Various Fibers. J. Civ. Eng. Forum 2017, 3, 383. [CrossRef]

19. Li, X.; Li, Y.; Yan, M.; Meng, W.; Lu, X.; Chen, K.; Bao, Y. Cyclic behavior of joints assembled using prefabricated beams and columns with Engineered Cementitious Composite (ECC). Eng. Struct. 2021, 247, 113115. [CrossRef]

20. Oinam, R.M.; Kumar, P.C.A.; Sahoo, D.R. Cyclic performance of steel fiber-reinforced concrete exterior beam-column joints. Earthq. Struct. 2019, 16, 533-546.

21. Annadurai, A.; Ravichandran, A. Seismic Behavior of Beam-Column Joint Using Hybrid Fiber Reinforced High-Strength Concrete. Iran. J. Sci. Technol. Trans. Civ. Eng. 2018, 42, 275-286. [CrossRef]

22. IS 13920:1993; Indian Standard Code on Criteria for Earthquake Resistant Design of Structures. Bureau of Indian Standards: New Delhi, India, 2002.

23. ACI Committee 318; Building Code Requirements for Structural Concrete. American Concrete Institute: Farmington Hills, MI, USA, 2005.

24. Zainal, S.M.I.S.; Hejazi, F.; Rashid, R.S.M. Enhancing the Performance of Knee Beam-Column Joint Using Hybrid Fibers Reinforced Concrete. Int. J. Concr. Struct. Mater. 2021, 15, 1-28. [CrossRef]

25. Dehghani, A.; Mozafari, A.R.; Aslani, F. Evaluation of the efficacy of using engineered cementitious composites in RC beamcolumn joints. Structures 2020, 27, 151-162. [CrossRef]

26. Yuan, F.; Pan, J.; Xu, Z.; Leung, C.K.Y. A comparison of engineered cementitious composites versus normal concrete in beamcolumn joints under reversed cyclic loading. Mater. Struct. 2012, 46, 145-159. [CrossRef]

27. Alwash, N.A.; Kadhum, M.M.; Mahdi, A.M. Rehabilitation of Corrosion-Defected RC Beam-Column Members Using Patch Repair Technique. Buildings 2019, 9, 120. [CrossRef] 
28. Bossio, A.; Fabbrocino, F.; Monetta, T.; Lignola, G.P.; Prota, A.; Manfredi, G.; Bellucci, F. Corrosion effects on seismic capacity of reinforced concrete structures. Corros. Rev. 2019, 37, 45-56. [CrossRef]

29. Santarsiero, G.; Manfredi, V.; Masi, A. Numerical Evaluation of the Steel Plate Energy Absorption Device (SPEAD) for Seismic Strengthening of RC Frame Structures. Int. J. Civ. Eng. 2020, 18, 835-850. [CrossRef]

30. Lowes, L.N.; Altoontash, A. Modeling Reinforced-Concrete Beam-Column Joints Subjected to Cyclic Loading. J. Struct. Eng. 2003, 129, 1686-1697. [CrossRef]

31. Brooke, N.J.; Ingham, J.M. Seismic Design Criteria for Reinforcement Anchorages at Interior RC Beam-Column Joints. ASCE 2013, 139, 1895-1905. [CrossRef]

32. Palermo, D.; Vecchio, F.J. Compression field modeling of reinforced concrete subjected to reversed loading: Formulation. $A C I$ Struct. J. 2003, 100, 2-234.

33. Rajagopal, P.S.S.; Thomas, H. Seismic behaviour evaluation of exterior beam-column joints with headed or hooked bars using nonlinear finite element analysis. Earthq. Struct. 2014, 7, 861-875. [CrossRef]

34. Park, S.; Mosalam, K.M. Experimental Investigation of Nonductile RC Corner Beam-Column Joints with Floor Slabs. J. Struct. Eng. 2013, 139, 1-14. [CrossRef]

35. Ramin, K.; Fereidoonfar, M. Finite Element Modeling and Nonlinear Analysis for Seismic Assessment of Off-Diagonal Steel Braced RC Frame. Int. J. Concr. Struct. Mater. 2015, 9, 89-118. [CrossRef]

36. IS 456:2000; Indian Standard Code on Plain and Reinforced Concrete. Bureau of Indian Standards: New Delhi, India, 2000.

37. ANSYS. ANSYS Manual; ANSYS INC: Canonsburg, PA, USA, 2009.

38. Alsayed, S.H.; Almusallam, T.H.; Al-Salloum, Y.A.; Siddiqui, N.A. Seismic Rehabilitation of Corner RC Beam-Column Joints Using CFRP Composites. J. Compos. Constr. 2010, 14, 681-692. [CrossRef]

39. Feng, J.; Wang, S.; Meloni, M.; Zhang, Q.; Yang, J.; Cai, J. Seismic Behavior of RC Beam Column Joints with 600 MPa High Strength Steel Bars. Appl. Sci. 2020, 10, 4684. [CrossRef]

40. Santarsiero, G.; Masi, A. Seismic Upgrading of RC Wide Beam-Column Joints Using Steel Jackets. Buildings 2020, 10, 203. [CrossRef]

41. Shang, X.-Y.; Yu, J.-T.; Li, L.-Z.; Lu, Z.-D. Strengthening of RC Structures by Using Engineered Cementitious Composites: A Review. Sustainability 2019, 11, 3384. [CrossRef]

42. Golias, E.; Zapris, A.G.; Kytinou, V.K.; Osman, M.; Koumtzis, M.; Siapera, D.; Chalioris, C.E.; Karayannis, C.G. Application of X-Shaped CFRP Ropes for Structural Upgrading of Reinforced Concrete Beam-Column Joints under Cyclic Loading-Experimental Study. Fibers 2021, 9, 42. [CrossRef]

43. Veismoradi, S.; Yousef-Beik, S.M.M.; Zarnani, P.; Quenneville, P. Seismic strengthening of deficient RC frames using self-centering friction haunches. Eng. Struct. 2021, 248, 113261. [CrossRef]

44. Ganasan, R.; Tan, C.G.; Ibrahim, Z.; Nazri, F.M.; Sherif, M.M.; El-Shafie, A. Development of Crack Width Prediction Models for RC Beam-Column Joint Subjected to Lateral Cyclic Loading Using Machine Learning. Appl. Sci. 2021, 11, 7700. [CrossRef]

45. Santarsiero, G. FE Modelling of the Seismic Behavior of Wide Beam-Column Joints Strengthened with CFRP Systems. Buildings 2018, 8, 31. [CrossRef] 